\title{
Psoriatic Arthritis
}

\section{Sacroiliitis}

- A 34-year-old patient

- Patient with chronic back pain

- Psoriatic polyarthritis with sacroiliitis
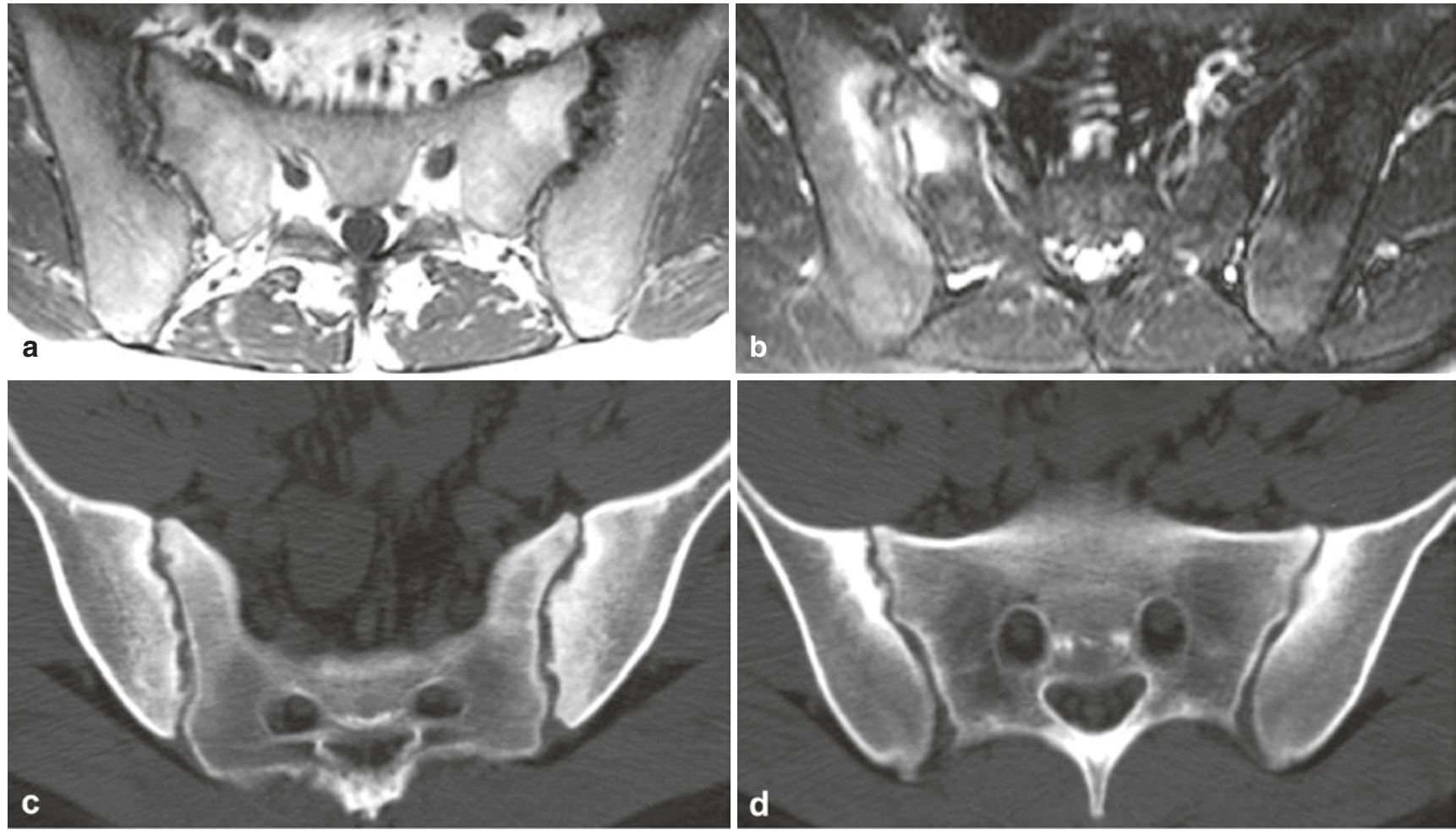

Fig. 1 Axial SE T1-weighted image (a), axial TSE T2-weighted image with fat saturation (b), CT images (c-d). Bilateral sacroiliitis in different stages. On the left side, there is adipous transformation of the bone marrow in the sacral side of the joint and osteosclerosis in the iliac side

(a, b). Subchondral edema and joint effusion of the right sacroiliac joint, indicating an active inflammatory stage $(\mathbf{a}, \mathbf{b})$. Note that $\mathrm{CT}$ evaluation shows bilateral subchondral osteosclerosis and microerosions (c, d) 